
\title{
25 Research Soure \\ Comparison of The Electrophysiological Characteristics of Tight Filum Terminale And Tethered Cord Syndrome
}

Naosuke Kamei ( $\square$ nahkamei@hiroshima-u.ac.jp )

Hiroshima University

Toshio Nakamae

Hiroshima University

Kazuyoshi Nakanishi

Nihon University

Taiki Morisako

Hiroshima University

Takahiro Harada

Hiroshima University

Toshiaki Maruyama

Hiroshima University

Nobuo Adachi

Hiroshima University

\section{Research Article}

Keywords: terminale, syndrome, conduction

Posted Date: November 3rd, 2021

DOl: https://doi.org/10.21203/rs.3.rs-977337/v1

License: (c) (i) This work is licensed under a Creative Commons Attribution 4.0 International License. Read Full License 


\section{Abstract}

This study aims to characterize tight filum terminale (TFT) in motor evoked potential (MEP) testing by comparing TFT patients with both tether cord syndrome (TCS) patients and healthy subjects. Fifty TFT patients, 18 TCS patients, and 35 healthy volunteers participated in this study. We recorded MEPs following transcranial magnetic stimulation from the bilateral abductor hallucis muscles as well as compound muscle action potentials and F-waves evoked by electrical stimulation of the tibial nerve from the bilateral abductor pollicis brevis muscles. The peripheral conduction time (PCT) was calculated from the latency of the compound action potential and F-wave. Furthermore, the central motor conduction time (CMCT) was calculated by subtracting PCT from MEP latency. TFT and TCS patients had a significantly longer MEP latency than healthy subjects. PCT in TFT patients were significantly longer than those in TCS patients or healthy subjects. Using the cut-off values for PCT, we were able to diagnose patients with TFT patients with a sensitivity of $72.0 \%$ and a specificity of $91.4 \%$. Prolonged PCT in the MEP test may be a useful indicator for TFT and suggests that MEP may be used as an adjunct diagnostic tool for TFT.

\section{Introduction}

Tether cord syndrome (TCS) is classically defined as a condition in which the tip of the conus medullaris is below the L2 vertebral body on magnetic resonance imaging (MRI) ${ }^{1}$. TCS spinal cord dysfunction is believed to be caused by pathological longitudinal stretching of the spinal cord ${ }^{2}$. Patients with TCS present with neurological symptoms, such as motor and sensory disturbances in the lower extremities, bladder and bowel dysfunction, and sexual dysfunction ${ }^{3}$. Some patients show neurological deficits similar to those of TCS despite normal location of the tips of the spinal cones. This condition is known as occult TCS ${ }^{4,5}$ or tight filum terminale (TFT) ${ }^{6,7}$.

In TFT, the symptoms are believed to be caused by spinal cord traction due to overstrain of the filum terminale ${ }^{8}$. TFT is difficult to diagnose due to its lack of imaging features ${ }^{5,9}$. However, we previously reported that MRI in the prone position detects TFT ${ }^{10}$. In the axial sectional image of the prone MRI of a TFT patient, the filum terminale separates from the cauda equina from the level of the L2 vertebra toward the periphery, which looks like a sunrise. This method was able to visualize a taut filum terminale although was not correlated with any neurological disorders. However, we have been measuring motor evoked potentials (MEPs) by transcranial magnetic stimulation for quantitative evaluation of neurological disorders ${ }^{11}$. Thus, this study aimed to clarify the characteristics of TFT patients in MEP measurement tests by comparing them with TCS to diagnose TFT.

\section{Methods}

\section{Participants}

Seventy-one patients diagnosed with TFT underwent MEP measurement and treatment between January 2008 and February 2020. Of these, 50 patients were included (TFT group). Those with Chiari 
malformation and scoliosis were excluded. A 3.0 Tesla MRI scanner was used to diagnose the TFT. The locations of the tip of the conus medullaris in TFT patients were the L1 vertebral body, L1-2 disc, and L2 vertebral body in 28,15 , and 7 cases, respectively. All patients with TFT had separation of the filum terminale from the cauda equina on lumbar MRI in the prone position (Fig. 1A) and had symptoms, such as dysuria, spinal stiffness, back pain, or numbness and weakness in the lower extremities. Moreover, all patients with dysuria were diagnosed as having neurogenic bladder by a thorough urological examination. Surgery to cut the filum terminale improved at least some of these symptoms.

The MEP results from patients with TFT were compared with those of 18 patients diagnosed with TCS who showed low conus medullaris on MRI and underwent MEP measurements during the same period (TCS group). The TCS group included both surgically and non-surgically treated patients, all of whom were clearly diagnosed based on MRI findings. All patients with TCS had symptoms, such as dysuria or paralysis of the lower extremities. In all patients with TCS, the tip of the spinal cone was located at the level of the sacrum (Fig. 1B). All MEP measurements were performed preoperatively in both groups. The MEP data of 35 healthy volunteers were used as controls (control group).

\section{Measurement of MEPs evoked by transcranial magnetic stimulation}

MEP measurements were performed as previously reported ${ }^{12,13}$. Surface recording electrodes were placed on the bilateral adductor muscles $(\mathrm{AH})$ using the standard ventral tendinous method. Transcranial magnetic stimulation was performed using a 14-cm-diameter circular coil (Model 200; Magstim, Whitland, United Kingdom), and evoked muscle potentials were recorded from the AH. The recording sensitivity was set at a vertical gain of $0.1 \mathrm{mV} / \mathrm{D}$ and a horizontal sweep of $10 \mathrm{~ms} / \mathrm{D}$. The magnetic stimulus intensity was set at $20 \%$ above the threshold for MEPs. The MEPs were recorded in four simultaneous repetitions on the left and right sides, and their latencies were measured (Fig. 2A). The longest latency, regardless of which side it was measured from, was used for evaluation. The tibial nerve at the ankle was stimulated with ultra-intense continuous current pulses ( $0.2 \mathrm{~ms}$ square-wave pulses), and compound muscle action potentials (CMAPs) and $F$ waves were recorded (Fig. 2A). A total of 32 serial responses were obtained, and the latency of the shortest F-wave was measured. A commercial system (Viking IV; Nicolet Biomedical, $\mathrm{Wl}$ ) was used to record the subjects' muscle responses. All muscle responses were recorded after passing through a band-pass filter from $0.52000 \mathrm{~Hz}$. Epochs of $100 \mathrm{~ms}$ after stimulation were digitized at a $5-\mathrm{kHz}$ sampling rate.

Peripheral conduction time (PCT), excluding the turnaround time (1 ms) in the spinal motoneurons, was calculated from the latencies of CMAPs and F-waves according to previous reports ${ }^{13,14}$. Further, PCT corrected for height was calculated using the following formula:

$\{($ latency of CMAPs + latency of F-waves -1$) / 2\} \times$ height / 163.0

The conduction time from the motor cortex to the motoneurons in the spinal cord (central motor conduction time; CMCT) was calculated by subtracting the PCT (uncorrected for height) from the onset 
latency of MEPs. These measurements were taken by an examiner who was blinded to the patient's history, clinical characteristics, and MRI results. The MEPs latency used in the evaluation was also corrected for height in the same way as PCT.

\section{Statistical analysis}

Longer values of left and right height-corrected MEP latency, height-corrected PCT, and CMCT were evaluated. All data are expressed as mean \pm standard deviation. One-way analysis of variance with Tukey's HSD post-hoc test was used to compare the groups. Receiver operating characteristic (ROC) curve analysis was used to determine the cut-off value for diagnosis, and Pearson's chi-square test was used to evaluate the male-to-female ratio among the three groups. The relationship between age, height, and MEP evaluation values was assessed using Pearson's product-moment correlation coefficient with 95\% confidence intervals. Statistical significance was set at $p<0.05$. Statistical analyses were performed using JMP® 15 (SAS Institute Inc., Cary, NC).

\section{Ethics}

The study protocol was approved by Ethical Committee for Research of Hiroshima University (Epi-138). The study was conducted in accordance with the 1964 Helsinki declaration and its later amendments or comparable ethical standards. All patients provided written informed consent to undergo MEP testing.

\section{Results}

\section{Demographic data}

The demographics of all groups, including sex, age, and height, are summarized in Table 1. No statistically significant difference was noted in the male-to-female ratio among the three groups ( $p=$ 0.440). The TFT group was significantly younger than the TCS ( $p=0.017)$ and control $(p=0.006)$ groups, and the control group was significantly younger than the TCS group $(p<0.001)$. The mean height of the TFT group was significantly shorter than that of the TCS $(p<0.001)$ and control $(p=0.002)$ groups; however, no significant difference was noted in height between the control and TCS groups $(p=0.964)$.

Table 1

Demographics of the subjects

\begin{tabular}{|c|c|c|c|c|}
\hline \\
\hline & Male & Female & Age (years) & Height (cm) \\
\hline TFT & 26 & 24 & $15.7 \pm 7.4$ & $154.0 \pm 14.6$ \\
\hline TCS & 12 & 6 & $36.7 \pm 17.9$ & $163.3 \pm 9.2$ \\
\hline Control & 17 & 18 & $22.9 \pm 5.1$ & $162.3 \pm 9.2$ \\
\hline
\end{tabular}


Height-corrected MEP latency, CMCT, and height-corrected PCT were compared between the three groups. The data for each group are summarized in Table 2. The MEP latencies in the TFT and TCS groups were significantly longer than those in the control group (both $p<0.001$ ), and no significant difference was noted between the TFT and TCS groups $(p=0.992)$ (Fig. 3A). The CMCT in the TCS group was significantly longer than that in the other two groups (both $p<0.001$ ); however, the CMCT in the TFT group was significantly longer than that in the control group $(p=0.047)$ (Fig. 3B). The TFT group had a significantly longer PCT than the other two groups (both $p<0.001$ ), and no significant difference was noted between the TCS and control groups ( $p=0.293)$ (Fig. 3C).

Table 2

Height-corrected MEP latency, CMCT and height-corrected PCT

\begin{tabular}{|llll|}
\hline & MEP latency $(\mathrm{ms})$ & CMCT $(\mathrm{ms})$ & PCT $(\mathrm{ms})$ \\
\hline TFT & $40.1 \pm 3.5$ & $14.0 \pm 1.8$ & $25.2 \pm 2.6$ \\
\hline TCS & $40.2 \pm 3.1$ & $17.9 \pm 2.2$ & $22.3 \pm 1.7$ \\
\hline Control & $36.2 \pm 1.6$ & $13.0 \pm 1.6$ & $23.2 \pm 0.7$ \\
\hline
\end{tabular}

In the ROC analysis, the cut-off value for CMCT to distinguish the TCS group from the control group was $15.8 \mathrm{~ms}$. The area under the curve (AUC) was 0.961 , with $83.3 \%$ sensitivity and $97.1 \%$ specificity (Fig. 4 A). Additionally, the cut-off value for PCT to distinguish the TFT group from the control group was $23.9 \mathrm{~ms}$. The AUC was 0.860 , with $72.0 \%$ sensitivity and $91.4 \%$ specificity (Fig. 4B).

\section{Correlation of age and height with MEP values}

To examine the effects of age and height on the MEP test values, we determined the correlations between these values in the control group. No correlation was observed between age and height-corrected MEP latency $(R=-0.105, p=0.548$, confidence interval $[C l]=-0.424-0.236)$ or $C M C T(R=-0.111, p=0.527, C l=$ $-0.428-0.231)$. However, there was a weak positive correlation between age and height-corrected PCT ( $R$ $=0.395, \mathrm{p}=0.019, \mathrm{Cl}=0.072-0.644)$ and a strong positive correlation between height and MEP latency $(\mathrm{R}=0.779, \mathrm{p}<0.001, \mathrm{Cl}=0.601-0.883)$ or $\mathrm{PCT}(\mathrm{R}=0.883, \mathrm{p}<0.001, \mathrm{Cl}=0.780-0.940)$. However, no correlation was observed between height and height-corrected MEP latency $(R=-0.068, p=0.699, \mathrm{Cl}=$ $-0.392-0.272)$ or height-corrected PCT $(R=0.135, p=0.440, C l=-0.208-0.448)$. Furthermore, there was a weak positive correlation between height and CMCT $(R=0.343, p=0.043, \mathrm{Cl}=0.012-0.607)$.

\section{Relationship between symptoms and each parameter in patients with TFT}

Of the 50 patients with TFT, spinal stiffness was present in all, dysuria in 31, back pain in 27, and lower extremity symptoms in 39. Patients complaining of back pain also had dysuria and lower extremity symptoms. The presence or absence of dysuria, back pain, lower extremity symptoms and other 
parameters (gender, height, MEP latency, CMCT, and PCT) are summarized in Table 3. No statistically significant difference was noted in each parameter between patients with and without these symptoms.

Table 3

Parameters with and without each symptom

\begin{tabular}{|c|c|c|c|c|c|c|c|c|}
\hline & & Male & Female & $\begin{array}{l}\text { Age } \\
\text { (years) }\end{array}$ & $\begin{array}{l}\text { Height } \\
\text { (cm) }\end{array}$ & $\begin{array}{l}\text { MEP } \\
\text { latency } \\
\text { (ms) }\end{array}$ & $\begin{array}{l}\text { CMCT } \\
\text { (ms) }\end{array}$ & $\begin{array}{l}\text { PCT } \\
\text { (ms) }\end{array}$ \\
\hline \multirow[t]{2}{*}{ Dysuria } & Present & 16 & 15 & $\begin{array}{l}14.4 \pm \\
6.0\end{array}$ & $\begin{array}{l}152.1 \\
\pm 13.7\end{array}$ & $40.1 \pm 3.6$ & $\begin{array}{l}13.6 \pm \\
1.6\end{array}$ & $\begin{array}{l}25.4 \\
\pm 3.1\end{array}$ \\
\hline & Absent & 10 & 9 & $\begin{array}{l}17.8 \pm \\
8.9\end{array}$ & $\begin{array}{l}156.9 \\
\pm 15.8\end{array}$ & $40.2 \pm 3.5$ & $\begin{array}{l}14.8 \pm \\
1.9\end{array}$ & $\begin{array}{l}24.8 \\
\pm 1.4\end{array}$ \\
\hline \multirow[t]{2}{*}{$\begin{array}{l}\text { Lower extremity } \\
\text { symptoms }\end{array}$} & Present & 22 & 17 & $\begin{array}{l}15.9 \pm \\
7.5\end{array}$ & $\begin{array}{l}154.2 \\
\pm 15.0\end{array}$ & $40.3 \pm 3.6$ & $\begin{array}{l}14.2 \pm \\
1.7\end{array}$ & $\begin{array}{l}25.2 \\
\pm 2.6\end{array}$ \\
\hline & Absent & 4 & 7 & $\begin{array}{l}14.8 \pm \\
7.2\end{array}$ & $\begin{array}{l}153.2 \\
\pm 13.8\end{array}$ & $39.7 \pm 3.3$ & $\begin{array}{l}13.5 \pm \\
2.0\end{array}$ & $\begin{array}{l}25.2 \\
\pm 2.4\end{array}$ \\
\hline \multirow[t]{2}{*}{ Back pain } & Present & 13 & 14 & $\begin{array}{l}16.0 \pm \\
7.6\end{array}$ & $\begin{array}{l}153.3 \\
\pm 14.8\end{array}$ & $40.3 \pm 3.9$ & $\begin{array}{l}14.1 \pm \\
1.7\end{array}$ & $\begin{array}{l}25.1 \\
\pm 3.0\end{array}$ \\
\hline & Absent & 13 & 10 & $\begin{array}{l}15.3 \pm \\
7.2\end{array}$ & $\begin{array}{l}154.7 \\
\pm 14.7\end{array}$ & $40.0 \pm 3.2$ & $\begin{array}{l}13.9 \pm \\
1.9\end{array}$ & $\begin{array}{l}25.3 \\
\pm 2.0\end{array}$ \\
\hline
\end{tabular}

\section{Discussion}

This study characterizes the features of TCS and TFT in MEPs. Compared with the other two groups, CMCT was significantly prolonged in the TCS group, while PCT was significantly prolonged in the TFT group. These cut-off values for CMCT and PCT could be used for the diagnosis of TCS and TFT.

TFT is often diagnosed at a young age because height gain results in increased tension in the terminal filaments, which often affects the medullary conus ${ }^{15}$. Patients with TCS were diagnosed at an even younger age than those with TFT; however, in this study, they underwent MEP testing because their symptoms worsened in adulthood. Therefore, the TFT group was significantly younger and shorter than the other two groups. We found no correlation between age and MEP latency or CMCT; however, a weak positive correlation was found between age and PCT. No significant correlation was noted between age and $\mathrm{CMCT}{ }^{16} 17$. In contrast, a previous report stated a positive but weak correlation between age and CMCT $(R=0.179, P=0.011){ }^{18}$. These findings suggest that the effect of age on CMCT prolongation in the TCS group is small. A positive correlation between age and PCT has also been previously reported ${ }^{19}$ 20 . This was associated with age-related peripheral nerve degeneration; however, since our study included few elderly individuals, this may explain why our study found only a weak correlation between age and PCT. In addition, although the TFT group was significantly younger than the other groups, the PCT in the TFT group was significantly longer, indicating that the prolonged PCT in the TFT group was not due to age. 
In the present study, we found a strong positive correlation between height and both MEP latency and PCT as well as a weak positive correlation between height and CMCT. These results were similar to previous reports ${ }^{18,20,21}$. In particular, leg CMCT has been reported to be more affected by height than hand $\mathrm{CMCT}^{22}$. Since no significant difference was observed in height between the TCS and control groups, the prolongation of CMCT in the TCS group that we observed may be due to factors other than height. Since MEP latency and PCT are greatly affected by height, the height-corrected values of each were evaluated in this study. No correlation was noted between height and height-corrected MEP latency or height-corrected PCT. Therefore, the prolongation of PCT in the TFT group appeared to be independent of height.

Previous reports have speculated that the delay in CMCT in patients with compressive myelopathy is not due to conduction delays in the corticospinal tract, but rather because spinal cord evoked potentials are attenuated by conduction blockade and take longer to excite spinal motor neurons ${ }^{12,23,24}$. It has been speculated that in patients with TCS, pronounced spinal traction damages the corticospinal tract at the head of motor neurons in the lumbar spinal cord, resulting in prolonged CMCT. The CMCT in patients with TFT was significantly shorter than that in patients with TCS although still significantly longer than that in healthy volunteers, suggesting that corticospinal tract involvement may be present in some patients with TFT. However, the prolongation of PCT was more pronounced than that of CMCT in patients with TFT. Since it is unlikely that the tension of the filum terminale would affect the cauda equina, it is possible that it affected the motor neurons in the lumbar spinal cord. Amyotrophic lateral sclerosis (ALS) is a disease that affects both the upper motor neurons (UMNs) in the brain and lower motor neurons (LMNs) in the spinal cord ${ }^{25}$. A previous report of patients with ALS classified them into four groups according to the presence or absence of physical signs of LMN and/or UMN involvement. Among these four groups, the latency of the F-wave was significantly prolonged in the group with physical signs of LMN compared with that of the group without physical signs of $L M N{ }^{26}$. This finding indicates that PCT may be prolonged by abnormalities in the motor neurons of the spinal cord. Thus, in patients with TFT, abnormalities of the motor neurons in the lumbar spinal cord may affect PCT prolongation. PCT was not prolonged in patients with TCS, despite the fact that motor neurons in the lumbar spinal cord may also be impaired in patients with TCS. The length of the peripheral nerve conduction pathway has a strong influence on PCT, as shown by the fact that height was strongly correlated with PCT. The fact that all patients with TCS have a spinal cord that extends to the sacrum and no cauda equina, thereby resulting in a shorter peripheral nerve conduction pathway, may be the reason why PCT was not prolonged in patients with TCS.

This study had some limitations. The main limitation is the lack of a reliable method to diagnose TFT. However, this makes this study valuable. Although bladder dysfunction may have been considered essential for diagnosing TFT, we have seen several cases wherein patients who had no urological problems and only complained of back pain and lower extremity symptoms had a dramatic improvement in their symptoms after surgery for TFT. We believe that such patients should not be overlooked. It has also been reported that some patients with TCS have normal bladder function and only experience symptoms in the lower extremities ${ }^{27} 28$. Therefore, in this study, we decided to diagnose the patient with 
TFT based on the fact that the symptoms were clearly improved by the surgery in addition to the features of TFT on MRI reported in a previous paper. Moreover, the difference in the presence or absence of bladder dysfunction did not affect the results of this study.

Since TCS and TFT are rare diseases, the number of cases sampled was not large. However, all previous reports of MEP for TCS or TFT have been based on intraoperative MEP monitoring and had a sample size equal to or less than that of this study. This study is the first report on the use of MEP in the diagnosis of TCS and TFT. We were unable to match the age and height of each group. Although the TFT group included several children, it was ethically challenging to include children as healthy volunteers. In addition to the variety in ages, our groups also differed in height. Therefore, we investigated and discussed the influence of age and height on the results and corrected for height, especially for MEP latency and PCT values, which are strongly influenced by height. Abnormalities of the motor neurons in the lumbar spinal cord as a mechanism of prolonged PCT in patients with TFT could not be directly demonstrated. During surgery, the filum tarminale was cut at the L5-S1 level; therefore, the lumbar spinal cord was not exposed, and spinal cord evoked potentials could not be assessed.

\section{Conclusions}

Prolonged PCT in the MEP test is characteristic of patients with TFT and may be a useful adjunct diagnostic tool.

\section{Declarations}

\section{Data availability}

The dataset created for this article is publicly available in the Harvard Dataverse repository: https://doi.org/10.7910/DVN/SEGOVA.

\section{Code availability}

The code implementing the model is available from the corresponding author on reasonable request.

\section{Acknowledgements}

Research presented in this article was supported by the European University Institute (EUI), Covid-related grant ("The Airport Factor: Assessing the Impact of International and National Aviation Mobility on the Spread of Covid-19", project submitted by the Migration Policy Centre).

\section{Author information}

E.R. developed the idea, coordinated the research project and wrote the first draft of the manuscript. A.F., A.R.S., L.G., L.B., S.I., S.S. and M.V. collected and validated the data. A.F., A.R.S., E.D., S.I., L.G., L.B. and 
E.R. conducted the statistical analyses. All authors discussed the results and edited the final manuscript. Corresponding author: ettore.recchi@eui.eu

\section{Additional information}

Correspondence and requests for materials should be addressed to N.K.

\section{References}

1 Raghavan, N., Barkovich, A. J., Edwards, M. \& Norman, D. MR imaging in the tethered spinal cord syndrome. AJR Am J Roentgenol 152, 843-852, doi:10.2214/ajr.152.4.843 (1989).

2 McVeigh, L. G. et al. Spinal column shortening for secondary tethered cord syndrome: radiographic, clinical, patient-reported, and urodynamic short-term outcomes. J Neurosurg Pediatr, 1-10, doi:10.3171/2020.11.PEDS20847 (2021).

3 Menezes, A. H., Seaman, S. C., lii, M. A. H., Hitchon, P. W. \& Takacs, E. B. Tethered spinal cord syndrome in adults in the MRI era: recognition, pathology, and long-term objective outcomes. J Neurosurg Spine, 113, doi:10.3171/2020.9.SPINE201453 (2021).

4 Selcuki, M. \& Coskun, K. Management of tight filum terminale syndrome with special emphasis on normal level conus medullaris (NLCM). Surg Neurol 50, 318-322; discussion 322 (1998).

5 Bao, N. et al. Tight filum terminale syndrome in children: analysis based on positioning of the conus and absence or presence of lumbosacral lipoma. Childs Nerv Syst 23, 1129-1134, doi:10.1007/s00381007-0376-8 (2007).

6 Metcalfe, P. D. et al. Treatment of the occult tethered spinal cord for neuropathic bladder: results of sectioning the filum terminale. J Uro/ 176, 1826-1829; discussion 1830, doi:10.1016/j.juro.2006.04.090 (2006).

7 Selden, N. R. Occult tethered cord syndrome: the case for surgery. J Neurosurg 104, 302-304, doi:10.3171/ped.2006.104.5.302 (2006).

8 Fabiano, A. J., Khan, M. F., Rozzelle, C. J. \& Li, V. Preoperative predictors for improvement after surgical untethering in occult tight filum terminale syndrome. Pediatr Neurosurg 45, 256-261, doi:10.1159/000228983 (2009).

9 Sato, T., Eguchi, Y., Enomoto, K. \& Murata, Y. Treating difficult-to-diagnose tight filum terminale: our experience with four patients. BMJ Case Rep 14, doi:10.1136/bcr-2020-239184 (2021).

10 Nakanishi, K. et al. Use of prone position magnetic resonance imaging for detecting the terminal filum in patients with occult tethered cord syndrome. J Neurosurg Spine 18, 76-84, doi:10.3171/2012.10.SPINE12321 (2013). 
11 Nakanishi, K. et al. Electrophysiological Assessment and Classification of Motor Pathway Function in Patients With Spinal Dural Arteriovenous Fistula. J Clin Neurophysio/ 36, 45-51, doi:10.1097/WNP.0000000000000526 (2019).

12 Nakanishi, K. et al. Significant correlation between corticospinal tract conduction block and prolongation of central motor conduction time in compressive cervical myelopathy. J Neurol Sci 256, 7174, doi:10.1016/j.jns.2007.02.009 (2007).

13 Nakanishi, K. et al. Assessment of central motor conduction time in the diagnosis of compressive thoracic myelopathy. Spine (Phila Pa 1976) 35, E1593-1598, doi:10.1097/BRS.0b013e3181d9e7a4 (2010).

14 Kimura, J. Principles and pitfalls of nerve conduction studies. Ann Neuro/ 16, 415-429, doi:10.1002/ana.410160402 (1984).

15 Komagata, M., Endo, K., Nishiyama, M., Ikegami, H. \& Imakiire, A. Management of tight filum terminale. Minim Invasive Neurosurg 47, 49-53, doi:10.1055/s-2003-812463 (2004).

16 Claus, D. Central Motor Conduction - Method and Normal Results. Muscle \& Nerve 13, 1125-1132, doi:DOI 10.1002/mus.880131207 (1990).

17 Mills, K. R. \& Nithi, K. A. Corticomotor threshold to magnetic stimulation: normal values and repeatability. Muscle Nerve 20, 570-576, doi:10.1002/(sici)1097-4598(199705)20:5<570::aidmus5>3.0.c0;2-6 (1997).

18 Imajo, Y. et al. Effects of differences in age and body height on normal values of central motor conduction time determined by F-waves. J Spinal Cord Med 40, 181-187, doi:10.1080/10790268.2015.1117193 (2017).

19 Booth, K. R. et al. Motor evoked potentials and central motor conduction: studies of transcranial magnetic stimulation with recording from the leg. Electroencephalogr Clin Neurophysio/ 81, 57-62, doi:10.1016/0168-5597(91)90104-6 (1991).

20 Cantone, M. et al. Age, Height, and Sex on Motor Evoked Potentials: Translational Data From a Large Italian Cohort in a Clinical Environment. Front Hum Neurosci 13, 185, doi:10.3389/fnhum.2019.00185 (2019).

21 Matsumoto, H. et al. Aging influences central motor conduction less than peripheral motor conduction: a transcranial magnetic stimulation study. Muscle Nerve 46, 932-936, doi:10.1002/mus.23430 (2012).

22 Tobimatsu, S., Sun, S. J., Fukui, R. \& Kato, M. Effects of sex, height and age on motor evoked potentials with magnetic stimulation. J Neuro/ 245, 256-261, doi:DOI 10.1007/s004150050215 (1998). 
23 Kaneko, K. et al. Mechanism of prolonged central motor conduction time in compressive cervical myelopathy. Clin Neurophysiol 112, 1035-1040, doi:10.1016/s1388-2457(01)00533-8 (2001).

24 Nakanishi, K., Tanaka, N., Fujiwara, Y., Kamei, N. \& Ochi, M. Corticospinal tract conduction block results in the prolongation of central motor conduction time in compressive cervical myelopathy. Clin Neurophysio/ 117, 623-627, doi:10.1016/j.clinph.2005.11.010 (2006).

25 Grad, L. I., Rouleau, G. A., Ravits, J. \& Cashman, N. R. Clinical Spectrum of Amyotrophic Lateral Sclerosis (ALS). Cold Spring Harb Perspect Med 7, doi:10.1101/cshperspect.a024117 (2017).

26 Mills, K. R. \& Nithi, K. A. Peripheral and central motor conduction in amyotrophic lateral sclerosis. $J$ Neurol Sci 159, 82-87, doi:10.1016/s0022-510x(98)00148-8 (1998).

27 Hoffman, H. J., Taecholarn, C., Hendrick, E. B. \& Humphreys, R. P. Management of lipomyelomeningoceles. Experience at the Hospital for Sick Children, Toronto. J Neurosurg 62, 1-8, doi:10.3171/jns.1985.62.1.0001 (1985).

28 Seki, T. et al. Surgical Outcome of Children and Adolescents with Tethered Cord Syndrome. Asian Spine J 10, 940-944, doi:10.4184/asj.2016.10.5.940 (2016).

\section{Figures}


A

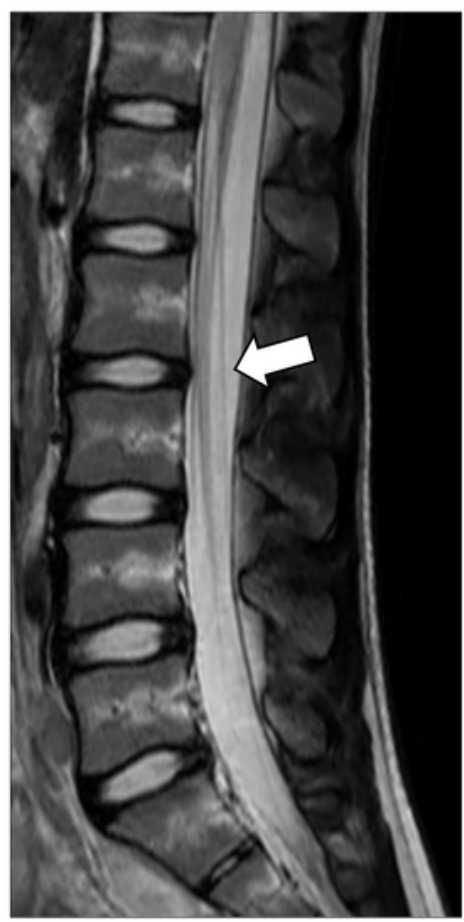

L2-3

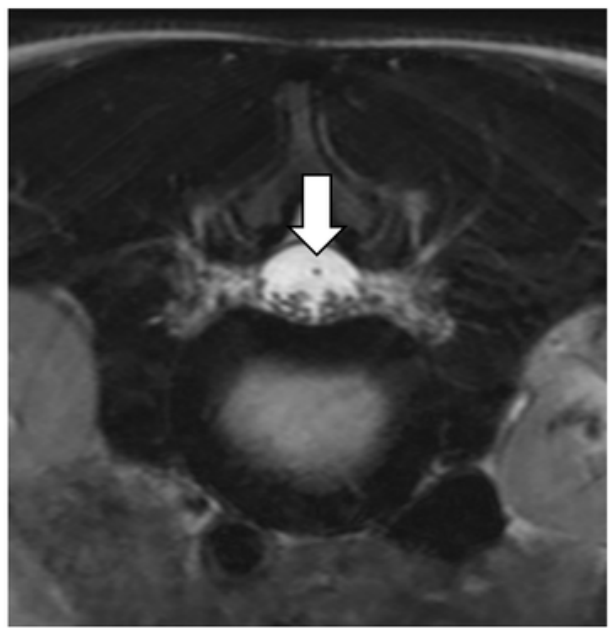

B

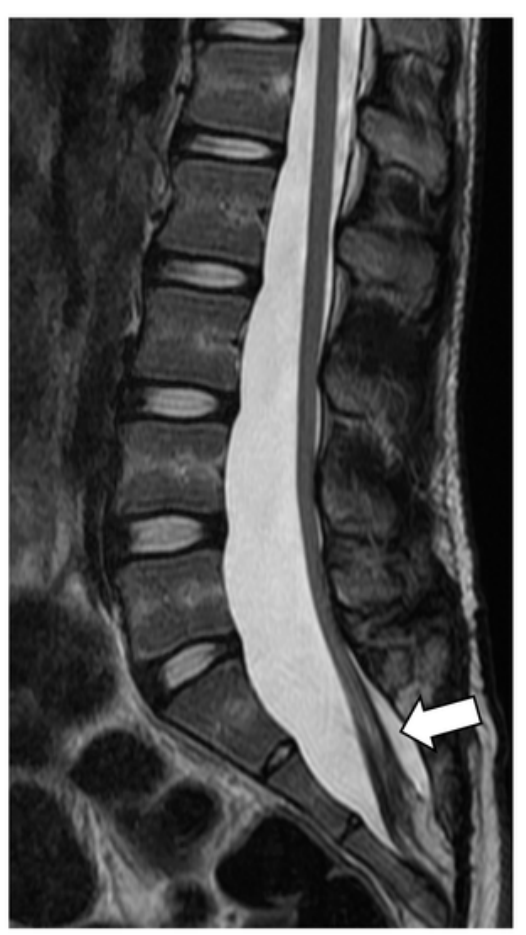

\section{Figure 1}

Magnetic resonance imaging (MRI) findings of patients with tight filum terminale (TFT) and tether cord syndrome (TCS). A: In the prone lumbar MRI of patients with TFT, only a taut filum terminale is located dorsally, while the cauda equina is located ventrally. The arrow indicates the filum terminale. B: MRI sagittal section of a patient with TCS. The spinal cord is located at the level of the sacrum. 
A

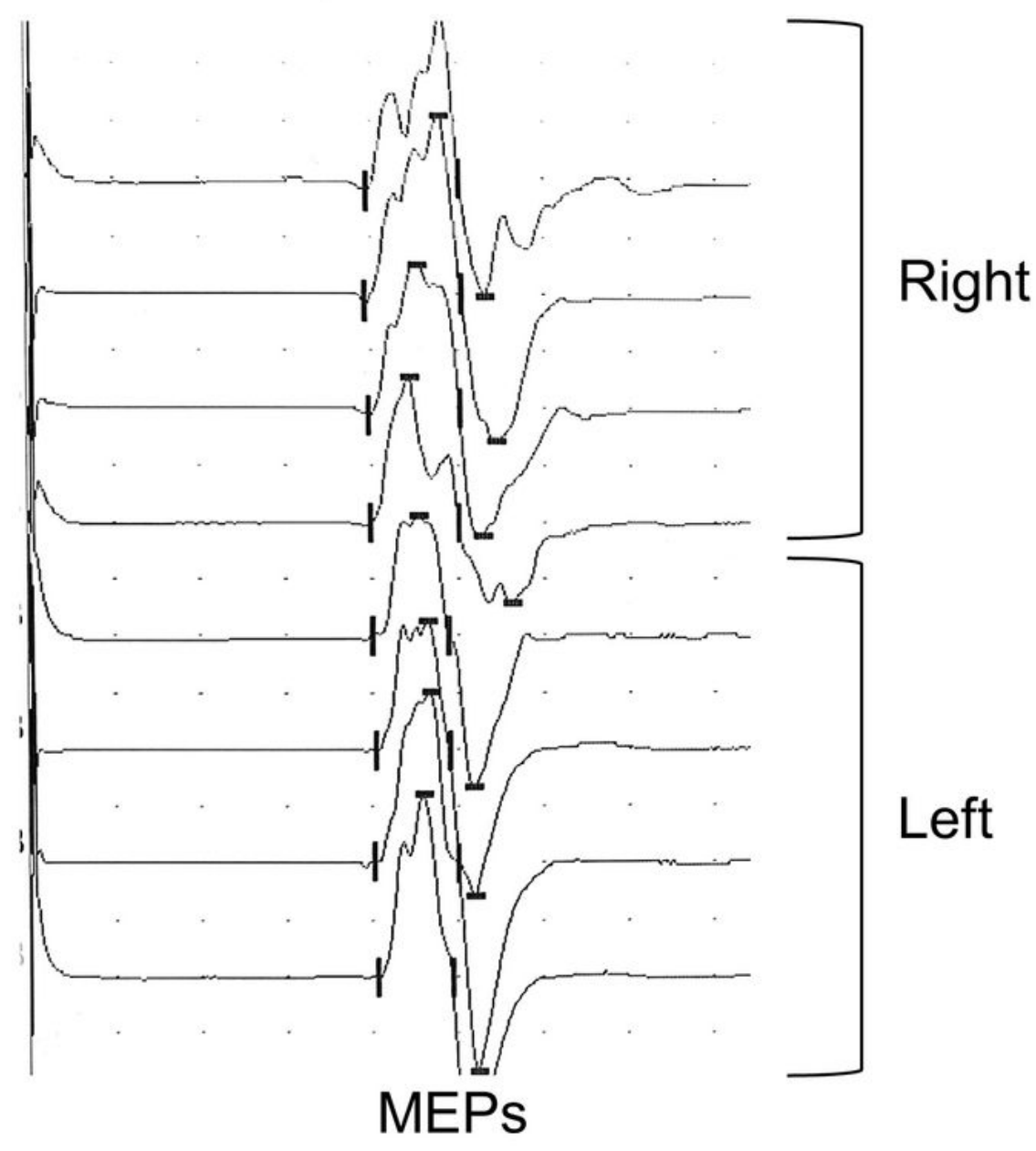

B

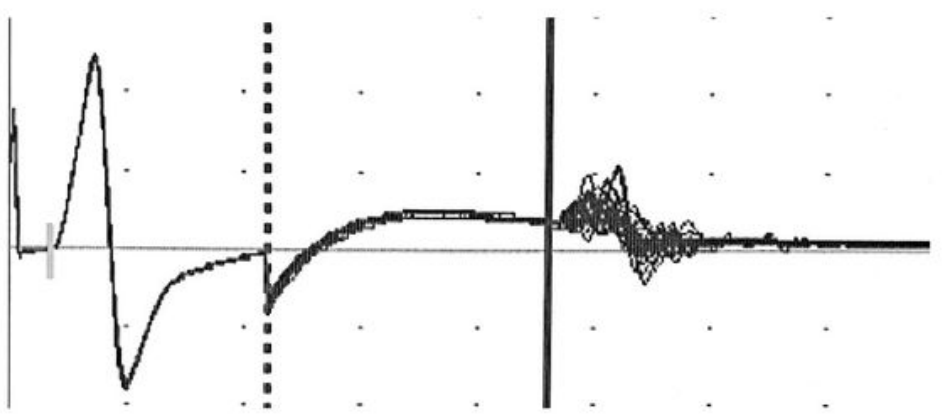

CMAPs

F-waves

\section{Figure 2}

A: The motor evoked potentials (MEPs) from the bilateral abductor hallucis muscles following transcranial magnetic stimulation. B: Compound muscle action potentials and F-waves evoked by electrical stimulation of the tibial nerve. 


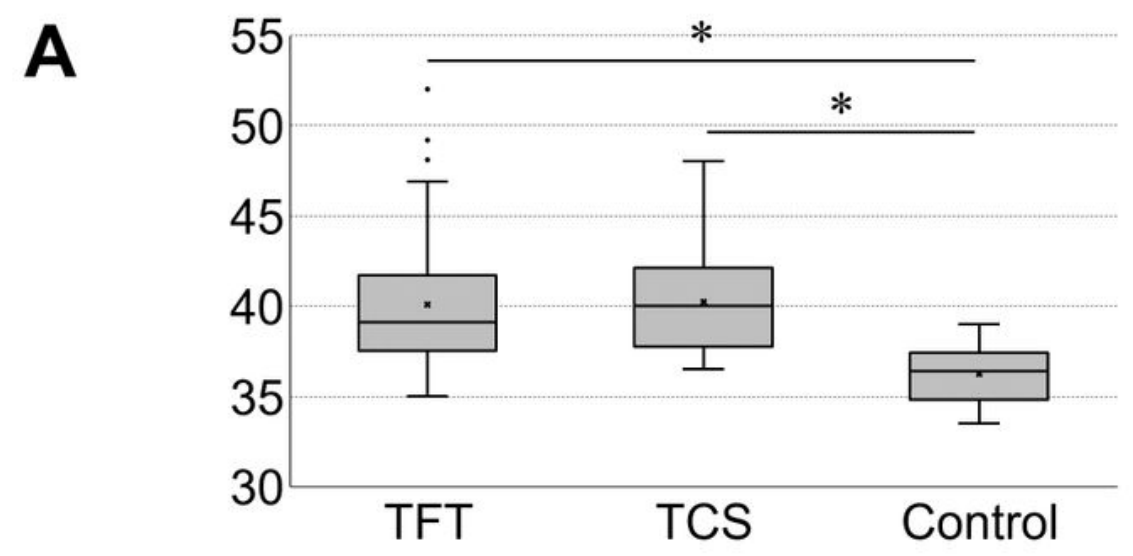

B
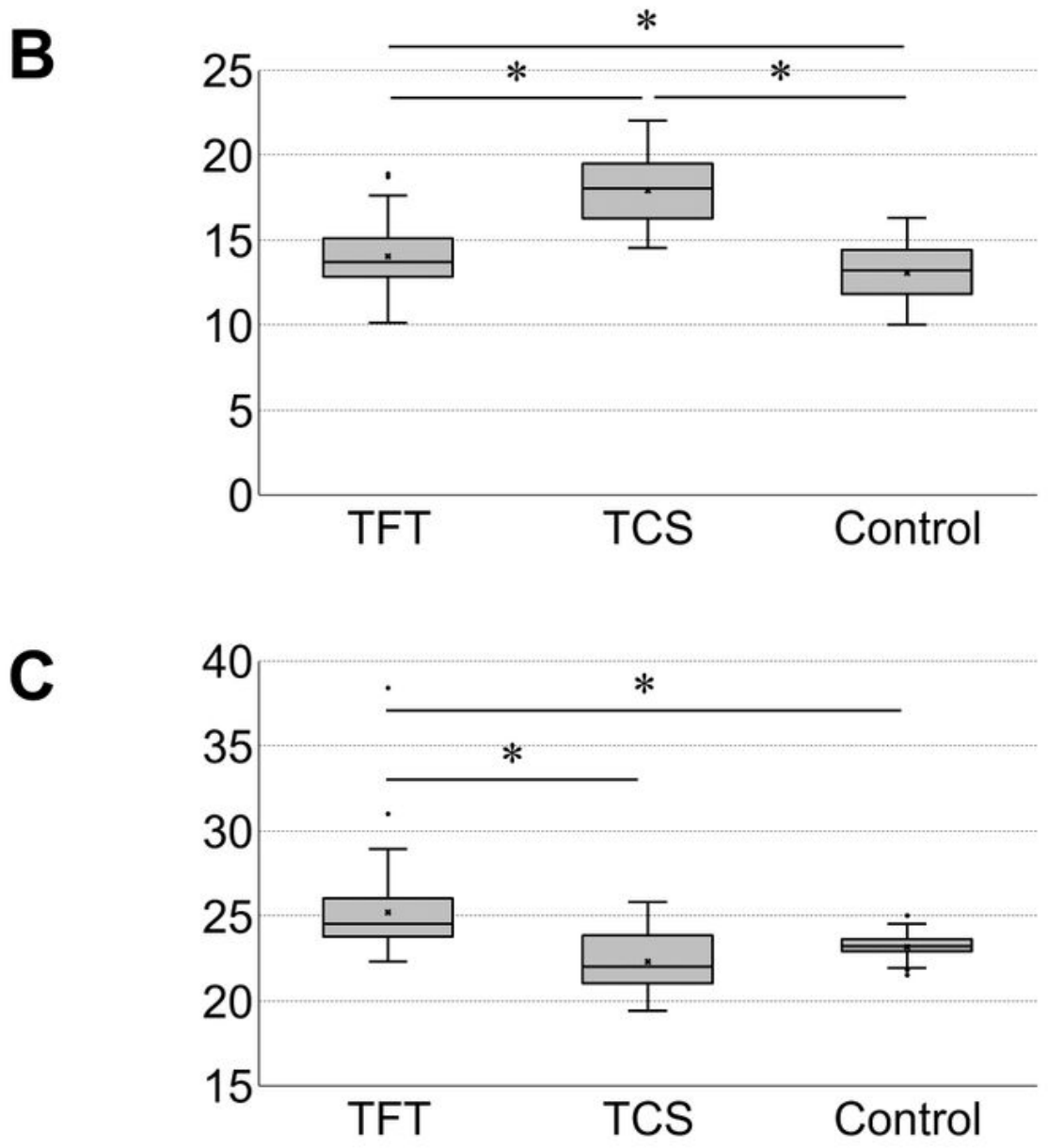

\section{Figure 3}

Box-and-whisker diagram of motor evoked potential (MEP) test results. A: Height-corrected latency of MEPs. The MEP latency in the tight filum terminale (TFT) and tether cord syndrome (TCS) groups was significantly longer than that in the control group. B: Central motor conduction time (CMCT). The CMCT in the TCS group was significantly longer than that in the TFT and control groups. C: Height-corrected 
peripheral conduction time (PCT). The PCT in the TFT group was significantly longer than that in the TCS and control groups.

\section{A CMCT for the diagnosis of TCS}

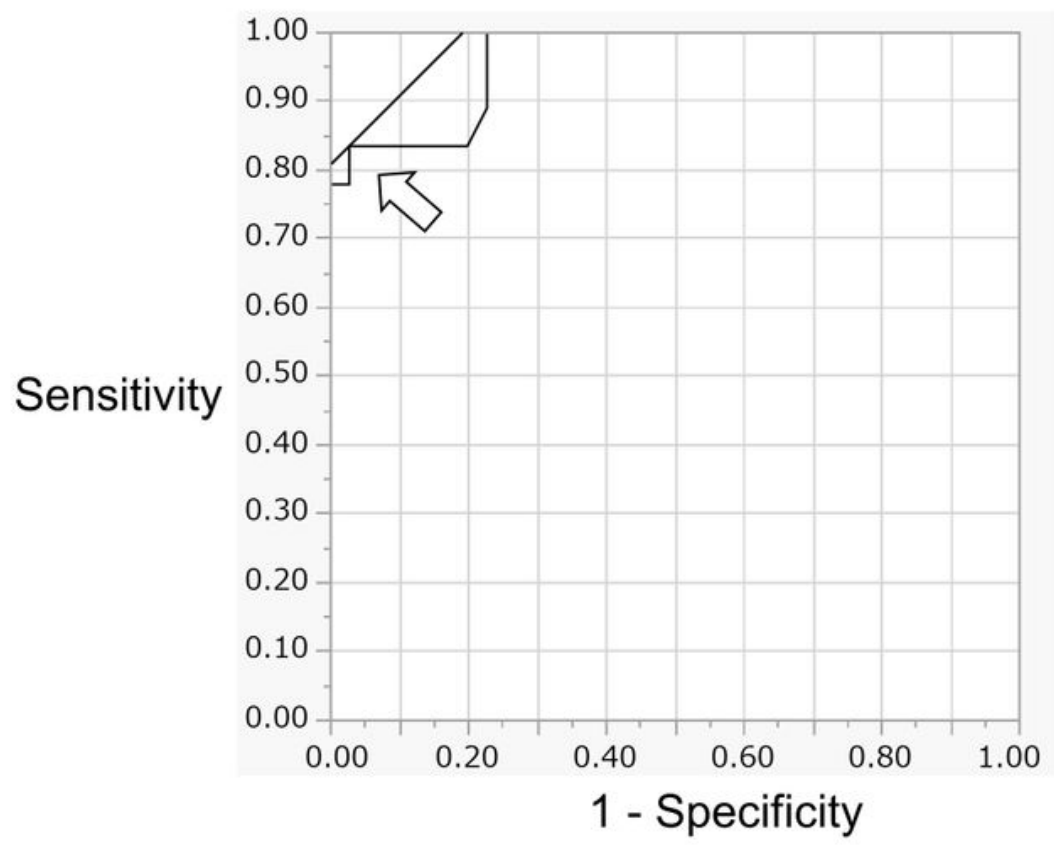

B PCT for the diagnosis of TFT

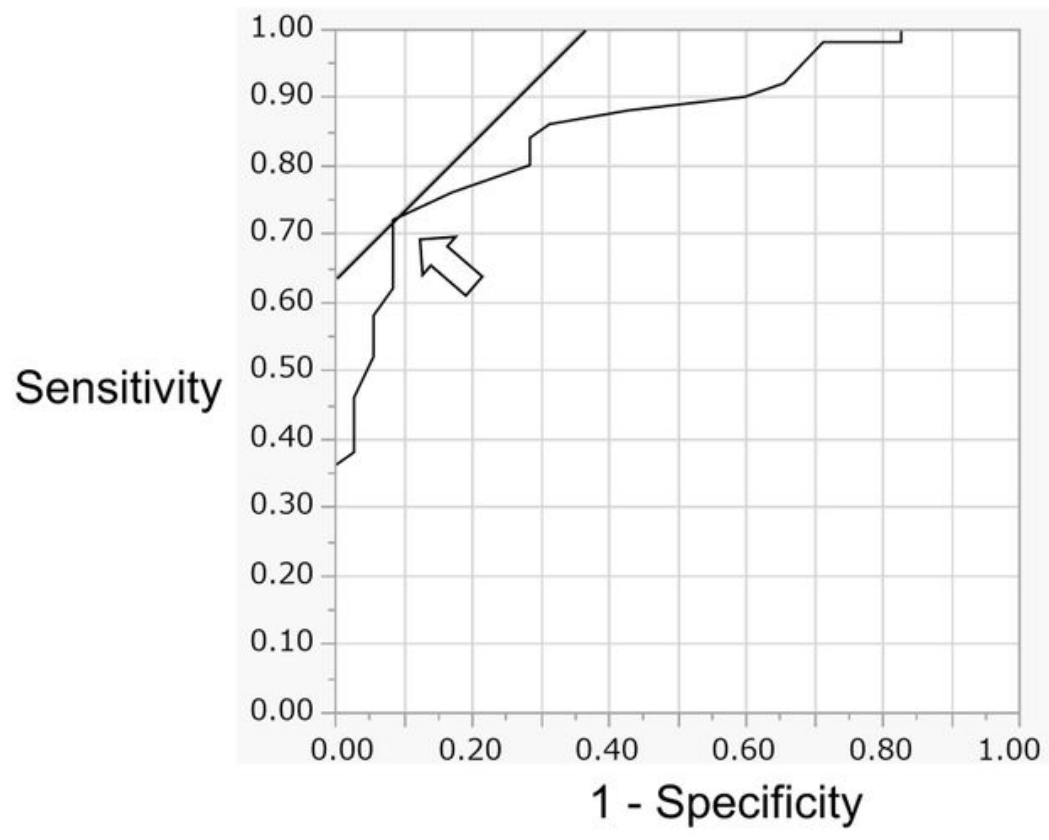

\section{Figure 4}

Receiver operating characteristic (ROC) curves and cut-off values. The arrows show the points wherein the "sensitivity - (1 - specificity)" is the largest, which was the cut-off value. A: The results of ROC analysis of central motor conduction time to distinguish patients with tether cord syndrome from healthy subjects. 
B: The result of ROC analysis of height-corrected peripheral conduction time to distinguish patients with tight filum terminale from healthy subjects. 